\title{
Management Are Aliens!
}

\author{
RUMORS AND STRESS DURING \\ ORGANIZATIONAL CHANGE
}

\author{
PRASHANT BORDIA \\ University of South Australia \\ ELIZABETH JONES \\ Griffith University, Australia \\ CINDY GALLOIS \\ VICTOR J. CALLAN \\ University of Queensland, Australia \\ NICHOLAS DIFONZO \\ Rochester Institute of Technology
}

\begin{abstract}
Rumors collected from a large public hospital undergoing change were content analyzed, and a typology comprising the following five broad types of change-related rumors was developed: rumors about changes to job and working conditions, nature of organizational change, poor change management, consequences of the change for organizational performance, and gossiprumors. Rumors were also classified as positive or negative on the basis of their content. As predicted, negative rumors were more prevalent than positive rumors. Finally, employees reporting negative rumors also reported more change-related stress as compared to those who reported positive rumors and those who did not report any rumors. The authors propose that rumors be treated as verbal symbols and expressions of employee concerns during organizational change.
\end{abstract}

Keywords: rumor; organizational change; communication

This research was supported by funding from the Australian Research Council. We are grateful to Simon L D. Restubog, Peta Ashworth, Elizabeth Hobman, Bernd Irmer, and Scott Krebs for help during various stages of the project and to Andrew DuBrin, Elizabeth George, Chip Heath, Nerina Jimmieson, and Ralph Rosnow for comments on earlier drafts. An earlier version of this article was presented at the 2003 Australian Industrial and Organizational Psychology Conference, Melbourne, Australia. Address correspondence to Prashant Bordia, School of Management, University of South Australia, GPO Box 247I. Adelaide, SA 5001. Australia; e-mail: prashant.bordia@unisa.edu.au

Group \& Organization Management, Vol. 31 No. 5, October 2006 601-621

DOI: $10.1177 / 1059601106286880$

2006 Sage Publications 
Rumors are common in most organizations (DiFonzo, Bordia, \& Rosnow, 1994; Michelson \& Mouly, 2002). A survey of public relations and corporate communications professionals revealed that managers are confronted with damaging or potentially damaging rumors almost once per week (DiFonzo \& Bordia, 2000). Rumors and the grapevine are reported by employees to be a major source of information about their company (Foehrenbach \& Rosenberg, 1983; Garnett, 1992; Harcourt, Richerson, \& Wattier, 1991). Advice on how to manage rumors in the workplace is also readily available (Danziger, 1988; Galant, 1990; Garnett, 1992).

Rumors can be generally understood as unverified statements regarding issues of topical significance (DiFonzo \& Bordia, 2002a, 2002b; Rosnow \& Kimmel, 2000). They can be distinguished from news in that rumors are unsubstantiated whereas news is presumably based on verified facts. Rumors also differ from other genres of informal communication, such as gossip, which tends to be about people and serves social and political agendas (Kurland \& Pelled, 2000; Noon \& Delbridge, 1993; Rosnow, 2001). Rumors can be about a range of phenomena (such as natural disasters, purported incidents of crime or violence, financial issues such as stock prices, or job-related matters such as layoffs) and are typically about issues of considerable importance to people (i.e., personal safety or livelihood).

Rumors are especially rampant during organizational change (DiFonzo et al., 1994; Hellweg, 1987; Isabella, 1990). They often preempt formal announcements by management, predicting the nature of the change (companies $X$ and $Y$ are planning to merge) or alleging dire consequences for employees (a large number of employees will be laid off; DiFonzo et al., 1994; Esposito \& Rosnow, 1983). Isabella (1990) found that in the early stages of organizational change, rumors predicted the possible direction in which the change may be heading. Similarly, rumors are noted for the speed with which they transmit through the informal network in organizations (Larkin \& Larkin, 1996). The popular business press is replete with rumors of mergers, layoffs, and CEO appointments or resignations (Cringely, 2001; Lingblom, 2001). In spite of the importance of rumors in staff opinion formation and effective change management (Larkin \& Larkin, 1994; Smeltzer, 1991), there is very little research on rumors during organizational change. For example, we are aware of no detailed thematic analysis of the types of rumor that spread during change. This article extends the literature on organizational change and communication in several ways. We present a detailed analysis of rumor content in the context of organizational change. Although we know rumors are widespread during organizational change, their precise nature and content have never been analyzed. In the research reported here, we collected rumors from a large metropolitan hospital undergoing internal restructuring 
and partial relocation to a new building. Through content analyzing rumors, the current research provides a typology of rumors during corporate change. This analysis provides insights into sources of employee uncertainty and anxiety during change. In addition, the current study adds to the literature on organizational change and personal transition by investigating the relationship of rumors with change-related stress. Thus, we relate rumor content to individual well-being during change.

In this study, we were guided by Dandridge, Mitroff, and Joyce's (1980) idea that rumors, as verbal symbols, reflect the psychological climate of the organization. Indeed, the psychological literature has long considered rumors to project the current anxieties, uncertainties, and prejudices of people involved in their spread. Rumors can also be understood to function in other ways (Rosnow, 2001), but the emphasis of this article concerns their symbolic role as a mirror of the change-related concerns of affected employees. The following section provides a review of the social and psychological literature on rumors.

\section{FACTORS AFFECTING RUMOR SPREAD}

The psychological precursors to rumor spread include uncertainty, thematic importance, anxiety, and belief (Rosnow, 1991). Uncertainty can be defined as a sense of doubt or confusion about ambiguous current events and their import for the future (DiFonzo \& Bordia, 1998). Uncertainty is an aversive psychological state and motivates strategies aimed at uncertainty reduction, such as information seeking (Ashford \& Black, 1996; Bordia, Hobman, Jones, Gallois, \& Callan, 2004; Rosnow, 1991). However, when information is unavailable from formal sources (such as news media or supervisors) or when these sources are not trusted, people resort to informal problem solving. Rumors are a product of this collective sense-making process (Bordia \& Rosnow, 1998; Shibutani, 1966). Of course, we are confronted with a range of uncertainties in everyday life, but we only feel the need to reduce uncertainty about matters of personal relevance or importance to us. Allport and Postman's (1947) basic law of rumor postulated that rumor activity is directly proportional to the ambiguity of an issue multiplied by its importance. Indeed, organizational rumors are typically about job security and working conditions, issues that are of high importance to most employees (DiFonzo et al., 1994).

Both situational and dispositional anxieties are associated with rumor spread (Rosnow, 1991). Walker and Beckerle (1987) found that research participants needed less prompting to report a rumor in conditions of highstate anxiety as compared to low-state anxiety. Similarly, rumor-related 
anxiety (i.e., anxiety on hearing a rumor) was significantly related to rumor transmission following the murder of a student on a university campus (Rosnow, Esposito, \& Gibney, 1988). Jaeger, Anthony, and Rosnow (1980) measured trait anxiety among college students prior to planting a rumor and found that rumor transmitters were higher on trait anxiety than nontransmitters (dead-enders).

Rumor transmission is positively related to belief in the rumor (Jaeger et al., 1980; Rosnow, 1991). To maintain personal credibility, people are more likely to pass on a rumor they believe to be true. However, the relationship between belief and transmission is moderated by anxiety. Belief appears to be most strongly related to transmission under moderate levels of anxiety (Rosnow et al., 1988). Critical evaluation of information is heightened under moderate levels of anxiety but may be suspended under low or high levels of anxiety. When people are not anxious, they may lack the motivation to assess credibility, and thus they may pass along rumors that they think are implausible. When overly anxious, any potentially useful scrap of information is employed, even those that seem implausible.

It is not surprising that rumors are rife during organizational change, which is marked by periods of uncertainty and anxiety about issues of great importance to employees (their jobs, working conditions, and career advancement). Management communication about change often falls short of fulfilling employees' need for information and predictability (DiFonzo \& Bordia, 1998; Schweiger \& DeNisi, 1991). Employees then rely more on rumors, which arise from an informal, collective sense-making process (DiFonzo et al., 1994; Shibutani, 1966).

\section{RUMOR CONTENT}

The analysis of rumor content has theoretical and practical benefits, and understanding why rumors acquire a particular content has been of interest to social scientists for many decades. This question received considerable attention around the time of the Second World War (Allport \& Postman, 1947; Knapp, 1944; Prasad, 1950). These authors concluded that the content of rumors reflects shared attitudes, concerns, and anxieties of the "rumor public" (people participating in the rumor spread). Thus, rumors that certain government officials were wasting fuel and food even during wartime rationing revealed mistrust and dislike of bureaucrats (Knapp, 1944). In recent times, rumors of e-mail viruses and alleged invasions of privacy abound on the Internet, reflecting our mistrust and fear of the unknown capabilities of electronic technology (Mitchell, 2001). Rumors 
serve to voice, justify, and even reinforce an attitude (Kapferer, 1990). For example, false rumors about Jews or Muslims (depending on whether the narrator is a Muslim or Jewish sympathizer) staying away from the World Trade Center on September 11, 2001, reflect mistrust of the other community (Hari, 2002). In addition, such rumors are often presented as evidence of and thereby reinforce beliefs regarding well-planned conspiracies by a rival or disliked group. In the organizational context, rumors have also been found to echo collective concerns. For example, rumors of staff turnover, job security, and Christmas bonuses reflect staff concerns about advancement opportunities, working conditions, and compensation (DiFonzo et al., 1994). During organizational change, managers struggle to deal with staff uncertainty and anxiety related to the nature and consequences of the change (Schweiger \& DeNisi, 1991). The knowledge of rumor content can provide change managers with valuable insights into the dominant concerns of employees and help them plan communication-based interventions to address these concerns.

Several authors have developed typologies to classify different types of rumors. During World War II, Knapp (1944) collected 1,089 rumors from the readers of Reader's Digest and classified these rumors into three broad types: wedge-driving, bogie, and pipe-dream rumors. Wedge-driving rumors included critical or prejudicial statements about another group (Jews are evading the draft). Bogie rumors were fear- and anxiety-driven statements of dreadful events (the entire Pacific Fleet was destroyed at Pearl Harbor). Pipe-dream rumors were wishful fantasies (there will be a revolution in Germany before summer). Rosnow, Yost, and Esposito (1986) divided rumors into two broad types: wish (rumors predicting desired consequences) or dread (rumors predicting harmful or disliked consequences). DiFonzo et al. (1994) interviewed managers in nine public and private sector organizations and identified five types of rumors: turnover, pecking order, job security, costly error, and consumer-concern rumors.

Although the literature provides us with some indication of the types of rumor to expect, there is a lack of systematic data-driven analysis of rumors during organizational change. In this study, we collected rumors from several hundred employees of an organization undergoing large-scale change and analyzed the content of these rumors. We expected to find wedgedriving, bogie, and pipe-dream rumors, and we wanted to uncover the precise form these rumors take in the organizational change context. Thus, we were guided by the following research question:

Research Question 1: What are the types of rumor during organizational change? 


\section{RUMORS AND STRESS}

As noted above, rumors spread under conditions that create anxiety and uncertainty. Thus, rumors are a consequence of stressful circumstances. However, rumors also cause stress (DiFonzo et al., 1994; DiFonzo \& Bordia, 2000). For example, rumors of food contamination, random acts of violence, natural disasters, and job layoffs cause panic among those who hear and believe these rumors. Thus, the relationship between stress and rumors can be considered reciprocal; stress can be an antecedent or a consequence of rumors. ${ }^{1}$

From the perspective of the rumor public, rumors can be negative or positive in content (Rosnow et al., 1986). A positive rumor is one that foretells wished-for or desired outcomes (e.g., there is going to be a larger than usual Christmas bonus) whereas a negative rumor describes a dreaded or undesirable happening or outcome (e.g., a large number of people have died in rioting by the rival ethnic group; there is going to be a large number of layoffs as a result of the organizational merger). Although there is no quantitative comparison of negative versus positive rumors in the context of organizational change, qualitative and anecdotal evidence suggests a preponderance of negative rumors associated with job security and staff turnover (DiFonzo et al., 1994; DiFonzo \& Bordia, 2000). This finding agrees with research findings regarding rumor valence. Although both negative and positive rumors exist, research evidence suggests that negative rumors are much more prevalent (Kamins, Folkes, \& Perner, 1997; Knapp, 1944; Walker \& Blaine, 1991). For example, a survey of consumers revealed that more than $90 \%$ of product-related rumors were negative (Kamins et al., 1997). Rosnow et al. (1986) found that the large majority of rumors surrounding union-management negotiations were negative in content. Walker and Blaine (1991) planted positive and negative rumors among university students. The rumors were matched on thematic importance. Negative rumors spread at more than twice the rate of positive rumors. The prevalence of negative rumors can be explained by considering rumors as collective attempts to regain informational or predictive control when faced with uncertain circumstances (Shibutani, 1966; Walker \& Blaine, 1991). By forecasting negative events, groups try to be prepared for worst-case scenarios. On the basis of this literature, we predicted that in the context of organizational change, there would be more negative rumors than positive rumors.

Hypothesis 1: There will be a greater frequency of negative rumors reported than positive rumors.

Given that negative rumors and stress coexist, levels of stress should be higher when negative rumors are present. Festinger (1957), in his classic work on cognitive dissonance, drew on the research on rumors and noted that rumors often justify and give meaning to existing anxiety. For example, 
negative rumors in the wake of an earthquake often foretell more earthquakes and thereby give voice to the fears and anxieties accompanying natural disasters (Prasad, 1935; Turner, 1994). Similarly, in times of organizational change, staff may feel anxious because of the uncertainty and loss of control associated with change (Callan, 1993; Jimmieson, Terry, \& Callan, 2004). This anxiety might be reflected in negative rumors predicting loss of jobs or status of work units as a consequence of the organizational change. These rumors in turn cause anxiety and stress among those who hear the rumors. Therefore, we predicted that negative rumors during change would be associated with greater stress than positive rumors or when there are no rumors.

Hypothesis 2: People who report negative rumors will be experiencing greater change-related stress than people who report positive rumors or do not report any rumors.

\section{METHOD}

\section{SAMPLE AND PROCEDURE}

The data on rumor and change-related stress were collected as part of a larger employee opinion survey at a metropolitan public hospital. The organization was undergoing major change during a period of 3 to 4 years, including the building of a new hospital, introduction of new technologies for patient care, internal restructuring, partial privatization, a reduction in number of patient beds, the introduction of multidisciplinary teams, and relocation of some departments to a new building. Data for this study were collected 1 year into the change implementation. All of the major new initiatives had been announced, and construction of the new building had commenced. The survey was mailed to all current employees in the organization $(N=3,200)$, including medical, nursing, administrative, and housekeeping staffs at all levels of the organizational hierarchy. A total of 1,610 completed surveys were returned (response rate of 50.3\%).

\section{MEASURES}

Change-related rumors. Respondents were asked to report change-related rumors using the following open-ended question: "Please describe the last rumor you heard about the changes going on at [this organization]."

Change-related stress. Stress was measured using Terry, Tonge, and Callan's (1995) four-item measure. This measure asked respondents to indicate how stressful the changes were using 6-point scales for the following bipolar dimensions: a) not at all stressful to extremely stressful, b) not at all disruptive to 
extremely disruptive, c) not at all upsetting to extremely upsetting, and d) not at all difficult to extremely difficult. The four items had high internal consistency (alpha $=.92)$ and were combined into a measure of change-related stress.

\section{RESULTS}

\section{RESEARCH QUESTION 1: TYPES OF RUMORS DURING ORGANIZATIONAL CHANGE}

Of those who returned completed surveys, 776 respondents answered the question about rumors. These responses were transcribed verbatim for content analysis. The content coding was conducted with a 12-category rumorcoding scheme. The categories were developed with an inductive, data-driven approach. Initial perusal of the rumors led to the development of several categories (e.g., categories of job loss and poor change management were immediately apparent). On further analysis, new categories were developed or earlier categories were refined or subsumed under another category with the aim of developing a categorization scheme of independent categories that would apply to the large majority of rumors.

A final set of 12 categories was considered to be an adequate representation of the sample of rumors and was used for the content analysis. A research assistant and an independent judge were trained in the coding scheme, with detailed explanations of the categories. The research assistant coded all 776 responses to the rumor question. To ascertain the reliability of coding, the independent judge coded a random $10 \%$ of rumors in each category. The consistency of coding was assessed by the coefficient kappa. The kappa values ranged from 0.74 to 1.0 for the 12 categories and were all statistically significant at $p<.001$, providing confidence in the reliability of the content analysis. Disagreements were discussed and resolved.

The 12 rumor categories were further collapsed into five broad rumor types with the aim of developing a generic typology of rumors during organizational change. This typology would be expected to be more generalizable to a wide range of organizations as compared to the more detailed 12-category coding scheme. Final results of the content analysis are presented in Table 1, including the rumor types, the rumor categories in each rumor type, the number of people who reported each rumor category, the definition of each category, and example rumors.

Changes to the job and working conditions. By far, the largest number of rumors were about changes to jobs $(n=377)$. Of these, the large majority (68\%, or $n=257$ ) belonged to the job loss rumor category. These rumors 
TABLE 1

Frequencies, Definitions, and Examples of the Rumor Types and Categories

\begin{tabular}{|c|c|c|c|}
\hline Rumor Type & Rumor Category & $\mathbf{n}$ & Definition (Example Rumor) \\
\hline \multirow[t]{7}{*}{$\begin{array}{l}\text { Changes to job } \\
\text { and working } \\
\text { conditions }\end{array}$} & Job loss & 257 & $\begin{array}{l}\text { Rumors of downsizing and job losses } \\
\text { ("operational officers to be downsized from } \\
300 \text { to } 100 \text { "), including as a result of } \\
\text { technology's replacing staff ("there will be fewer } \\
\text { staff required because of new technology") }\end{array}$ \\
\hline & $\begin{array}{l}\text { Negative work } \\
\text { practice changes }\end{array}$ & 31 & $\begin{array}{l}\text { Increased workload for less pay ("have to do } \\
\text { more work for less money"), increased } \\
\text { accountability of work units ("each unit will } \\
\text { be responsible for its own budget, including } \\
\text { salaries") }\end{array}$ \\
\hline & $\begin{array}{l}\text { Negative impact } \\
\text { on career }\end{array}$ & 29 & $\begin{array}{l}\text { Lack of career advancement ("no career } \\
\text { structure for nurses") and negative changes } \\
\text { to terms of employment (“designed so staff } \\
\text { can be put on contract") }\end{array}$ \\
\hline & $\begin{array}{l}\text { Loss of job } \\
\text { facilities }\end{array}$ & 24 & $\begin{array}{l}\text { Loss of work or job-related facilities ("staff } \\
\text { car park to go") }\end{array}$ \\
\hline & $\begin{array}{l}\text { Improved work } \\
\text { environment }\end{array}$ & 17 & $\begin{array}{l}\text { Improved work environment conditions } \\
\text { ("there will be lots of lifts and the toilets will } \\
\text { be self-flushing") }\end{array}$ \\
\hline & $\begin{array}{l}\text { No staff } \\
\text { reductions }\end{array}$ & 5 & $\begin{array}{l}\text { No job losses or an increase in the number of } \\
\text { jobs ("increased number of nursing staff") }\end{array}$ \\
\hline & $\begin{array}{l}\text { Positive work } \\
\text { practice changes }\end{array}$ & 5 & $\begin{array}{l}\text { Increased teamwork (“all people will be } \\
\text { working in a unit as a team") and } \\
\text { technological upgrade ("voice recognition } \\
\text { for X-ray reporting") }\end{array}$ \\
\hline $\begin{array}{l}\text { Nature of } \\
\text { organizational } \\
\text { change }\end{array}$ & $\begin{array}{l}\text { Changes to the } \\
\text { structure and } \\
\text { nature of the } \\
\text { organization }\end{array}$ & 147 & $\begin{array}{l}\text { Conjectures about work unit closures and } \\
\text { mergers ("mental health will be collocated } \\
\text { with geriatrics") and partial privatization } \\
\text { of the organization ("the new hospital will } \\
\text { be a private hospital") }\end{array}$ \\
\hline $\begin{array}{l}\text { Poor change } \\
\text { management }\end{array}$ & $\begin{array}{l}\text { Poor change } \\
\text { management }\end{array}$ & 89 & $\begin{array}{l}\text { Statements criticizing change planning and } \\
\text { management practices, such as wastage of } \\
\text { money and resources ("they are paying an extra } \\
\$ 1 \text { million to put an 'aesthetically pleasing' } \\
\text { bend in the building"), poor judgment and } \\
\text { decision making and management ineptitude } \\
\text { ("the hospital is well over budget"), cynicism } \\
\text { about the reasons behind the change }\end{array}$ \\
\hline
\end{tabular}

(continued) 
TABLE 1

(continued)

\begin{tabular}{|c|c|c|c|}
\hline Rumor Type & Rumor Category" & $\mathbf{n}$ & Definition (Example Rumor) \\
\hline & & & $\begin{array}{l}\text { ("the hospital is being moved to the CEO's } \\
\text { home state to save relocating his mates"), and } \\
\text { cynicism about change-related communication } \\
\text { and consultation ("our division head has } \\
\text { already made up his mind and that } \\
\text { consultation process is a sham") }\end{array}$ \\
\hline
\end{tabular}

Consequences of Negative changes the change for organizational performance

to service

delivery

Positive changes to service delivery

Gossip-rumors

Gossip and innuendo about individuals

Uncoded statements
Not a rumor or unclassifiable
49 Negative statements relating to downgrading of patient services ("the ceasing of patient enquiry line") and downgrading of equipment ("there will be no oxygen available in bathrooms, only portable oxygen")

4 Positive statements about advances in patient care ("the hospital will be doing cardiac transplants within 5 years")

10 Statements alleging staff turnover ("the CEO was leaving") and nefarious activities ("the manager was trying to make savings in the department to justify getting himself a taxpayer-funded car")

109 Statements about the preponderance of rumors ("far too many to write in the space provided"), respondent did not listen to rumors ("don't listen to rumors-no time"), and other unclassifiable statements ("all bad")

Total 776

a. The content analysis was conducted using these categories.

predicted varying numbers of job losses in different parts of the organization (such as "operational officers to be downsized from 300 to 100 ," " 125 jobs to go in the admin stream," "no job is safe, no job for anyone over 40 ," "70\% of the admin staff would lose their jobs," "there will be fewer staff required because of new technology"). In a similar vein, 29 respondents reported rumors alleging negative impact of the changes on their career or advancement opportunities and terms of employment ("no career structure for nurses," "designed so staff numbers can be put on contract," "we will be required to reapply for our jobs"). Compared to the large number of people reporting job loss rumors, there were only 5 respondents who reported rumors of no job loss or increase in the number of jobs (such as "increased number of nursing staff"). Other rumors predicted loss of work or job-related facilities ("staff car 
park to go," "there will be no on-site child care"), improved work environment ("there will be lots of lifts and the toilets will be self-flushing," "there [is] going to be a new staff swimming pool as well as a gym").

Finally, there were both positive and negative rumors about changes to work practices. Negative changes included increased workload for less pay ("have to do more work for less money," "overtime going") and increased accountability of work units ("each unit will be responsible for its own budget, including salaries"). Positive changes included increased teamwork ("all people will be working in a unit as a team") and technological upgrade ("voice recognition for X-ray reporting").

Nature of organizational change. The second-most frequent type of rumor ( $n=147$ ) involved conjectures about the precise nature of the organizational change. These rumors predicted departmental closures and mergers ("mental health will be collocated with geriatrics") and partial privatization of the hospital ("the new hospital will be a private hospital," "privatization of certain service delivery areas," "contracting out of [occupational health and safety] jobs"). Note that in these categories of rumor, the respondents did not express clear approval or disapproval of the rumored nature of the change. These were neutral statements. However, they did reflect a great deal of uncertainty and a variety of interpretations about the nature and outcome of change.

Poor change management. Many rumors $(n=89)$ alleged incompetent change management. These rumors claimed wastage of money and resources, especially for inappropriate reasons ("they are paying an extra \$1 million to put an 'aesthetically pleasing' bend in the building," "not enough money for equipment," "[outpatient department] does not have a home in the new hospital and no computer booking system but McDonalds has been allocated prime space"), poor judgment and decision making and management ineptitude ("the hospital was well over budget," "building running behind schedule," "the architect, financers, and management can't agree on the floor layout for new hospital," "management are aliens"), and cynicism about the reasons for the change ("the hospital is being moved to the CEO's home state to save relocating his mates") and about change-related communication and consultation ("we are moving, we are not moving, we are moving . .." "our division head has already made up his mind and that consultation process is a sham").

Consequences of the change for organizational performance. Fifty-three respondents reported rumors that referred to the effects of the changes on the organization's ability to provide patient care. There were many more negative consequences reported $(n=49)$ as compared to positive consequences $(n=4)$. 
Rumors of negative consequences included downgrading of patient services ("the ceasing of patient enquiry line," "the bed numbers are decreasing by 200 ") and equipment ("there will be no oxygen available in bathrooms, only portable oxygen"). Positive consequences included advancements in patient care ("the hospital will be doing cardiac transplants within 5 years").

Gossip-rumors. The final type of rumor included mainly gossip and innuendo about individuals, such as staff turnover ("the CEO was leaving") and nefarious activities ("the manager was trying to make savings in the department to justify getting himself a taxpayer-funded car"). These statements tended to be about individuals, hence were labeled gossip. However, the targets were typically people who play an important role in change-related decision making (CEO, unit manager), and the gossip statements were clearly in the context of the change implementation. Therefore, we called these statements gossip-rumors (see DiFonzo \& Bordia, 2000, for a similar categorization).

Uncoded. About $14 \%$ of the responses were unclassifiable $(n=109)$. They mainly included statements about the preponderance of rumors ("far too many to write in the space provided," "too many to remember") or that the respondent did not listen to rumors ("don't listen to rumors-no time," "I ignore rumors") and other unclassifiable statements ("all bad," "theater floor has little to do with rumor").

\section{HYPOTHESIS 1: FREQUENCY OF POSITIVE VERSUS NEGATIVE RUMORS}

Hypothesis 1 predicted that more respondents would report a negative rumor compared to a positive rumor. The 12 rumor categories were divided into positive and negative rumors on the basis of whether the rumor mentioned something positive (e.g., increase in the number of jobs, better patient service, improved work conditions) or negative (job loss, downgrading of job-related facilities, or poor change management). Rumor categories that could not be clearly classified as negative or positive (such as the nature of organizational change) were not included in this analysis. Table 2 shows the number of people who reported a positive or a negative rumor. As predicted, the number of people reporting a negative rumor $(n=479)$ was significantly greater than the number of people reporting a positive rumor $(n=31), \chi^{2}(1)=393.5, p<.001$.

\section{HYPOTHESIS 2: CHANGE-RELATED STRESS AND POSITIVE VERSUS NEGATIVE RUMORS}

Hypothesis 2 predicted that people who report negative rumors would experience greater change-related stress than people who report positive or 
TABLE 2

Number of Positive Rumor, Negative Rumor, and No-Rumor Statements and the Average Levels of Change-Related Stress Reported in Each Category

\begin{tabular}{lrcc}
\hline \hline & \multicolumn{3}{c}{ Change-Related Stress } \\
\cline { 2 - 4 } Category & $\mathrm{n}$ & $\mathrm{M}$ & $\mathrm{SD}$ \\
\hline Positive $^{\mathrm{a}}$ & 31 & 3.05 & 1.20 \\
Negative $^{\mathrm{b}}$ & 479 & $3.51^{\circ}$ & 1.33 \\
No rumor & 834 & 3.19 & 1.33 \\
\hline
\end{tabular}

NOTE: Higher values indicate more stress. Mean with an asterisk is significantly different from the other two.

a. Positive rumors include rumors relating to improved work environment, positive work practice changes, no staff reductions, and positive changes to service delivery.

b. Negative rumors include rumors relating to staff reductions, negative impact on career, negative work practice changes, loss of job facilities, poor change management, and negative changes to service delivery.

no rumors. Table 2 shows the average levels of stress reported by respondents who reported a positive or negative rumor or did not report any rumors (i.e., did not answer the question). To test Hypothesis 2, we conducted $t$ tests comparing the negative rumor condition with positive and no-rumor conditions. Given the large difference in sample sizes, we did not assume equal variances. We also computed the product-moment correlation $r$ as an effect size estimate (Rosnow, Rosenthal, \& Rubin, 2000). As predicted, change-related stress in the negative rumor group (mean $=3.51$ ) was significantly higher than the positive rumor group (3.05), $t(35.20)=2.06, p<.03$ (one-tailed), effect size $r=.35$, and the no-rumor group (3.18), $t(978.31)=4.62, p<.001$ (one-tailed), effect size $r=.14$. Thus, Hypothesis 2 was supported. Also, note that the effect size estimate suggests that the difference in stress between negative and positive rumor groups is greater than the difference between negative and no-rumor groups.

\section{DISCUSSION}

\section{CONTENT OF RUMORS DURING ORGANIZATIONAL CHANGE}

The purpose of this research was to analyze the different types of rumor that circulate during organizational change and to develop a typology of change-related rumors. Although the presence of rumors during change has been noted in the academic and practitioner literatures, to our knowledge, this is the first time a detailed analysis of rumors has been conducted. 
Our analysis of the 776 responses yielded 12 categories of rumors. These 12 categories were further collapsed into five broad types: rumors about changes to job and working conditions, nature of organizational change, consequences of the change for organizational performance, poor change management, and gossip-rumors. The rumors revealed typical areas of concern to employees during change, such as job security, changes to job roles, future career opportunities, and their ability to perform effectively in the changing work environment. The rumors also reflected common types of uncertainties, such as the precise nature and outcome of change and its impact on their job and organizational performance.

The largest number of rumors were about changes to job and working conditions. Of these, by far the most common rumor was about layoffs. Job security tends to be one of the major concerns for employees during times of organizational restructuring (Adkins, Werbel, \& Farh, 2001), and rumors regarding the numbers and types of job to go proliferate (Cringely, 2001; Greenhalgh \& Rosenblatt, 1984). Similarly, other rumors were about the negative impact on career advancement opportunities and downgraded employment and work conditions. The second-most frequent rumor type involved predictions and conjectures regarding the nature of organizational change. There is a great deal of uncertainty during change, and rumors that predict the precise nature and direction of change are widespread. These rumors provide predictability and structure to the uncertainty surrounding a changing work environment (Isabella, 1990).

The third rumor type consisted of rumors claiming poor change management. These rumors, often dramatic and colorful, claimed mismanagement of the change process and revealed mistrust of the motivations for change. These types of sentiment are key elements of an attitude of cynicism toward organizational change (Wanous, Reichers, \& Austin, 2000). Cynicism about change involves a pessimistic outlook regarding the outcomes of the change and a lack of confidence in the ability of those responsible for managing change. These rumors express and reinforce the attitude by alleging mismanagement and overall incompetence of the change managers (budget blowouts, misplaced priorities).

The fourth rumor type consisted of rumors regarding the consequences of change for the delivery of services and the overall performance of the organization. These rumors reflect concerns among the employees regarding the impact of the change on their ability to provide efficient service to customers and general service outcomes. The fifth rumor type involved statements about individuals and were therefore labeled gossip-rumor. Gossiping about turnover and staff reshuffles, especially senior management, are very common during restructuring. Much of this type of gossip is harmless, although it does play an important role in organizational politics and power plays 
(Kurland \& Pelled, 2000; Noon, 2001). However, sometimes gossip can acquire a serious dimension, for example, when the gossip alleges misconduct or takes the form of collective bullying (Zapf, 1999). Finally, several statements were not classifiable as rumors. Nevertheless, some of these responses were interesting as they revealed the widespread nature of rumors ("too many to write in the space provided").

\section{NEGATIVE RUMORS AND STRESS}

As predicted, there were significantly more negative rumors than positive rumors. These findings support previous rumor research (Kamins et al., 1997; Rosnow et al., 1986). There are two explanations for the prevalence of negative rumors. First, rumors can be construed as attempts by people to regain control of their circumstances. Faced with a situation that is personally relevant (employment) but uncertain and unpredictable (as in times of restructuring), employees feel a loss of control. Most employees are unable to change their circumstances (stop the restructuring) and thus lack primary control. Instead, they strive for secondary control by trying to adapt to the changing environment (Rothbaum, Weisz, \& Snyder, 1982). One form of secondary control is interpretive control, defined as "the ability to interpret events so as to better understand and accept them" (Rothbaum et al., 1982, p. 11). Rumors predicting the likely course of future events are attempts to regain a sense of predictability and understanding of these events. That is, faced with an uncertain future, employees attempt to acquire secondary (interpretive) control by predicting negative and often worst-case scenarios so that these events do not come as a surprise (Walker \& Blaine, 1991). Weenig, Groenenboom, and Wilke (2001) found that negative information is more likely to be passed on when it helps friends avert harmful consequences. Thus, rumors of job loss can be conceived of as attempts by employees to assert control and predictability over an uncertain future. These rumors are collective warnings of possible harmful events.

Second, the negative rumors justify and give meaning to the anxiety experienced by employees in a changing and unpredictable work environment. Heath (1996) found that bad news is more likely to be conveyed if it matches with the affective tone of the general topic. Negative rumors of layoffs or poor working conditions are congruent with the anxiety and grief that often accompany large-scale organizational change (Armenakis \& Bedeian, 1999; Callan, 1993). Supporting this line of reasoning, our results showed that those reporting negative rumors also reported greater change-related stress than those who reported positive rumors or did not report any rumors (Hypothesis 2). In other words, rumors matched the affective state of the respondents.

The finding regarding greater stress among those exposed to negative rumors confirms the harmful nature of rumors for employee morale. Note 
that we are not claiming that rumors caused this stress but that there is likely to be a reciprocal relationship between negative rumors and stress. This finding can also be taken as tentative support for the idea that rumors as verbal symbols describe the psychological climate of the organization. The preponderance of negative rumors points to change-related distress among employees. The finding that negative rumors were associated with higher ratings on the stress measure supports this interpretation.

\section{THEORETICAL AND PRACTICAL IMPLICATIONS}

Although rumors can have damaging effects, they are not an aberrant phenomenon (Michelson \& Mouly, 2002). Rather, rumors are an essential element of the collective informal sense-making process. Research on rumors is important not only for improving management of organizational communication but also for understanding the "deep structures" underlying employee collective behavior in response to turbulent work environments (Heracleous \& Barrett, 2001; Light, 1979). Following Dandridge et al. (1980), we recommend that rumors be accorded the status of organizational symbols. Dandridge et al. classified symbols as verbal (myths, legends, and rumors), behavioral (actions such as rites and rituals), or material (logo, decor, and status symbols) and noted that all symbols have three functions: description (they represent an aspect of the organization), energy control (they evoke and channel affect and motivation), and system maintenance (they provide direction and meaning to organizational existence). Rumors as verbal symbols fulfill all three functions. They express the dominant concerns of employees (description), vent anxiety but also create stress (energy control), and garner support for collective action for or against organizational goals (system maintenance). Conceived of in this way, rumors can be a useful gauge of the organizational climate. Indeed, the psychological literature considers rumors as a more revealing indicator of dominant attitudes than self-report methodologies, such as opinion surveys (Allport \& Postman, 1947; Knapp, 1944; Rosnow \& Fine, 1976). Whereas the latter could be biased by self-presentation motives, rumors act as an "inkblot test," revealing anxieties and prejudices not easily measured by surveys.

The findings of this study have several practical implications. The typology presented here should help managers anticipate the kinds of rumor they may encounter during organizational change. For example, if there is uncertainty about the nature and direction of change, rumors may take the form of predictions about the change, such as the units to be merged and numbers of staff to be laid off (Isabella, 1990; Smeltzer, 1991). More important, managers can expect these rumors to be largely negative in content. Reinforcing previous recommendations in the literature, we advocate that managers pay close 
attention to the content of rumors rather than dismiss them as idle chitchat. Rumors can provide useful insights into dominant concerns or sources of anxiety among staff. Moreover, if left unaddressed, rumors can cause a great deal of harm. For example, rumors of alleged incompetence on the part of the senior management can undermine trust and confidence in the leadership and reinforce a climate of cynicism. Rumor management requires a careful and considered approach. A ham-fisted clamping down or banning of rumors is unlikely to work and may instead create resentment. Rumors are integral to the social fabric and cannot be legislated away. On the other hand, rumors can cause real damage to reputations and create unnecessary panic and therefore do require managing. We recommend that managers try to prevent rumors by adopting open and participatory communication practices (Armenakis \& Harris, 2002; DiFonzo \& Bordia, 1998). Moreover, staff training on the nature, causes, and consequences of rumors can make employees informed participants and consumers of the grapevine. If potentially harmful rumors do arise, managers should take active steps to fight the rumor, including strong denials from credible sources (DiFonzo et al., 1994; Bordia, DiFonzo, \& Schulz, 2000) and clear instructions to staff to desist from spreading defamatory rumors.

\section{LIMITATIONS AND FUTURE DIRECTIONS}

This research relied on self-report data regarding rumors. We tried to minimize memory effects by asking respondents to report a recent rumor. However, negative rumors could be more salient and as a result more easily retrieved from memory, which might explain the larger number of negative rumors. Future research should use other means of collecting data on rumors, such as participant observation or a diary-based method to record rumors. There is also a need for longitudinal research to allow stronger inferences to be drawn regarding the antecedents (such as uncertainty and anxiety) and consequences (such as morale, trust, and cynicism) of rumors in organizations. Although this study has identified the content of rumors during change, we did not investigate whether the rumors were true or false. Rumors are by definition of indeterminate veracity, but they may turn out to be true or false. To allow managers and employees to be informed consumers of the grapevine, it would be useful to know the levels of accuracy of information in the informal channels of communication. Future research needs to identify conditions that lead to accurate versus inaccurate rumors. For example, DiFonzo and Bordia (2002a) found that rumors evolving out of high levels of discussion among skeptical employees tend to be highly accurate. Finally, although rumors can never be completely eliminated, managers have to often combat harmful rumors. Research-based strategies for preventing and controlling harmful rumors 
would be of considerable assistance to change managers responsible for communicating and implementing change.

\section{NOTE}

1. This way of conceptualizing a bidirectional relationship between rumors and stress is similar to the reciprocal or transactional relationship between stressors and stress proposed in several major theoretical models of stress (Lazarus \& Folkman, 1984; Schuler, 1982).

\section{REFERENCES}

Adkins, C. L., Werbel, J. D., \& Farh, J.-L. (2001). A field study of job insecurity during a financial crisis. Group \& Organization Management, 26, 463-483.

Allport, G. W.. \& Postman, L. J. (1947). The psychology of rumor. New York: Holt, Rinehart \& Winston.

Armenakis, A. A., \& Bedeian, A. G. (1999). Organizational change: A review of theory and research in the 1990s. Journal of Management, 25(1), 293-315.

Armenakis, A. A., \& Harris, S. G. (2002). Crafting a change message to create transformational readiness. Journal of Organizational Change Management, 15, 169-183.

Ashford, S., \& Black, J. (1996). Proactivity during organizational entry: The role of desire for control. Journal of Applied Psychology, 81, 199-214.

Bordia, P., Difonzo, N., \& Schulz, C. (2000). Denying rumors of organizational closure: Honesty is the best policy. Journal of Applied Social Psychology, II, 2309-2232.

Bordia, P., Hobman, E., Jones, E., Gallois, C., \& Callan, V. (2004). Uncertainty during organizational change: Types, consequences, and management strategies. Journal of Business and Psychology, 18(4), 507-532.

Bordia, P., \& Rosnow, R. L. (1998). Rumor rest stops on the information highway: A naturalistic study of transmission patterns in a computer-mediated rumor chain. Human Communication Research, 25(2), 163-179.

Callan, V. J. (1993). Individual and organizational strategies for coping with organizational change. Work and Stress, 7, 63-75.

Cringely, R. X. (2001). Fresh layoff rumors abound. Infoworld, 23(37), 12.

Dandridge, T. C., Mitroff, I., \& Joyce, W. F. (1980). Organizational symbolism: A topic to expand organizational analysis. Academy of Management Review, 5, 77-82.

Danziger, E. (1988). Minimize office gossip. Personnel Journal, 67, 31-33.

DiFonzo, N.. \& Bordia, P. (1998). A tale of two corporations: Managing uncertainty during organizational change. Human Resource Management, 37, 295-303.

DiFonzo, N., \& Bordia, P. (2000). How top PR professionals handle hearsay: Corporate rumors, their effects, and strategies to manage them. Public Relations Review, 26, 173-190.

DiFonzo, N., \& Bordia, P. (2002a). Corporate rumor activity, belief, and accuracy. Public Relations Review, 28, 1-19.

DiFonzo, N., \& Bordia, P. (2002b). Rumors and stable-cause attribution in prediction and behavior. Organizational Behavior and Human Decision Processes, 88, 785-800.

DiFonzo, N., Bordia, P., \& Rosnow, R. L. (1994). Reining in rumors. Organizational Dynamics, 23(1), 47-62.

Esposito, J. L., \& Rosnow, R. L. (1983, April). Corporate rumors: How they start and how to stop them. Management Review, pp. 44-49. 
Festinger, L. (1957). A theory of cognitive dissonance. Evanston, IL: Row, Peterson.

Foehrenbach, J., \& Rosenberg, K. (1983). How are we doing? Journal of Communication Management, 12(1), 3-11.

Galant, D. (1990, March). Responding to rumors. Institutional Investor, p. 58.

Garnett, J. L. (1992). Coping with rumors and grapevines: Tactics for public personnel management. Review of Public Personnel Administration, 12, 42-49.

Greenhalgh, L., \& Rosenblatt, Z. (1984). Job insecurity: Toward conceptual clarity. Academy of Management Review, 9, 438-448.

Harcourt, J., Richerson, V., \& Wattier, M. J. (1991). A national study of middle managers' assessment of organization communication quality. Journal of Business Communication, $28,348-365$.

Hari, J. (2002, December 31). Well, they would say that, wouldn't they? Australian Financial Review, p. 42.

Heath, C. (1996). Do people prefer to pass along good or bad news? Valence and relevance of news as predictors of transmission propensity. Organizational Behavior and Human Decision Processes, 68(2), 79-94.

Hellweg, S. A. (1987). Organizational grapevines. In B. Dervin \& M. J. Voigt (Eds.), Progress in communication sciences (Vol. 8, pp. 213-230). Norwood, NJ: Ablex.

Heracleous, L., \& Barrett, M. (2001). Organizational change as discourse: Communicative actions and deep structures in the context of information technology implementation. Academy of Management Journal, 44, 755-778.

Isabella, L. A. (1990). Evolving interpretations as a change unfolds: How managers construe key organizational events. Academy of Management Journal, 33, 7-41.

Jaeger, M. E., Anthony, S., \& Rosnow, R. L. (1980). Who hears what from whom and with what effect: A study of rumor. Personality and Social Psychology Bulletin, 6, 473-478.

Jimmieson, N. L., Terry, D. J., \& Callan, V. J. (2004). A longitudinal study of employee adaptation to organizational change: The role of change-related information and change-related self-efficacy. Journal of Occupational Health Psychology, 9, 11-27.

Kamins, M. A., Folkes, V. S., \& Perner. L. (1997). Consumer responses to rumors: Good news, bad news. Journal of Consumer Psychology, 6, 165-187.

Kapferer, J. N. (1990). Rumors: Uses, interpretations, and images. New Brunswick, NJ: Transaction.

Knapp, R. H. (1944). A psychology of rumor. Public Opinion Quarterly, 8, 22-27.

Kurland, N. B., \& Pelled, L. S. (2000). Passing the word: Toward a model of gossip and power in the workplace. Academy of Management Review, 25, 428-438.

Larkin, T. J., \& Larkin, S. (1994). Communicating change. How to win employee support for new business directions. New York: McGraw-Hill.

Larkin, T. J., \& Larkin, S. (1996). Reaching and changing frontline employees. Harvard Business Review, 74(3), 95-104.

Lazarus, R. S., \& Folkman, S. (1984). Stress, appraisal, and coping. New York: Springer.

Light, D. (1979). Surface data and deep structure: Observing the organization of professional training. Administrative Science Quarterly, 24, 551-561.

Lingblom, M. (2001, February 5). Razorfish awash in layoff rumors. Computer Reseller News, 931, 86 .

Michelson, G., \& Mouly, V. S. (2002). "You didn't hear it from us but . . .: Towards an understanding of rumour and gossip in organisations. Australian Journal of Management, 27, 57-65.

Mitchell, S. (2001, March 6). Crying cyberwolf. The Australian, pp. 53, 54.

Noon, M. (2001). Suggested revisions to Kurland and Pelled's model of gossip and power. Academy of Management Review, 26, 173-174. 
Noon, M., \& Delbridge, R. (1993). News from behind my hand: Gossip in organizations. Organization Studies, 14(1), 23-37.

Prasad, J. (1935). The psychology of rumour: A study relating to the great Indian earthquake of 1934. British Journal of Psychology, 26, 1-15.

Prasad, J. (1950). A comparative study of rumours and reports in earthquakes. British Journal of Psychology, 4I, 129-144.

Rosnow, R. L. (1991). Inside rumor: A personal journey. American Psychologist, 46, 484-496.

Rosnow, R. L. (2001). Rumor and gossip in interpersonal interaction and beyond: A social exchange perspective. In R. M. Kowalski (Ed.), Behaving badly: Aversive behaviors in interpersonal relationships (pp. 203-232). Washington, DC: American Psychological Association.

Rosnow, R. L., Esposito, J. L., \& Gibney, L. (1988). Factors influencing rumor spreading: Replication and extension. Language and Communication, 8(1), 29-42.

Rosnow, R. L., \& Fine, G. A. (1976). Rumor and gossip: The social psychology of hearsay. New York: Elsevier.

Rosnow, R. L., \& Kimmel, A. J. (2000). Rumor. In A. E. Kazdin (Ed.), Encyclopedia of psychology (Vol. 7, pp. 122-123). New York: Oxford University Press/American Psychological Association.

Rosnow, R. L., Rosenthal, R., \& Rubin, D. B. (2000). Contrasts and correlations in effect-size estimation. Psychological Science, II(6), 446-453.

Rosnow, R. L., Yost, J. H., \& Esposito, J. L. (1986). Belief in rumor and likelihood of rumor transmission. Language and Communication, 6(3), 189-194.

Rothbaum, F., Weisz, J. R., \& Snyder, S. S. (1982). Changing the world and changing the self: A two-process model of perceived control. Journal of Personality and Social Psychology, 42, 5-37.

Schuler, R. S. (1982). An integrative transactional process model of stress in organizations. Journal of Occupational Behaviour, 3, 5-19.

Schweiger, D. M., \& DeNisi, A. S. (1991). Communication with employees following a merger: A longitudinal field experiment. Academy of Management Journal, 34(1), 110-135.

Shibutani, T. (1966). Improvised news: A sociological study of rumor. Indianapolis, IN: Bobbs-Merrill.

Smeltzer, L. R. (1991). An analysis of strategies for announcing organization-wide change. Group and Organization Studies, 16, 5-24.

Terry, D. J., Tonge, L., \& Callan, V. J. (1995). Employee adjustment to stress: The role of coping resources, situational factors and coping responses. Anxiety, Stress and Coping, 8, 1-24.

Turner, R. H. (1994). Rumor as intensified information seeking: Earthquake rumors in China and the United States. In R. R. Dynes \& K. J. Tierney (Eds.), Disasters, collective behavior, and social organization (pp. 244-256). Newark: University of Delaware Press.

Walker, C. J., \& Beckerle, C. A. (1987). The effect of anxiety on rumor transmission. Journal of Social Behavior and Personality, 2, 353-360.

Walker, C. J., \& Blaine, B. (1991). The virulence of dread rumors: A field experiment. Language and Communication, 11, 291-297.

Wanous, J. P., Reichers, A. E., \& Austin, J. T. (2000). Cynicism about organizational change: Measurement, antecedents, and correlates. Group \& Organization Management, 25, 132-153.

Weenig, M. W. H., Groenenboom, A. C. W. J., \& Wilke, H. A. M. (2001). Bad news transmission as a function of the definitiveness of consequences and the relationship between communicator and recipient. Journal of Personality and Social Psychology, 80(3), 449-461.

Zapf, D. (1999). Organisational, work group related, and personal causes of mobbing/bullying at work. International Journal of Manpower, 20(1/2), 70-85. 
Prashant Bordia is an associate professor in the School of Management at the University of South Australia. His research interests include uncertainty and rumor management during organizational change.

Elizabeth Jones is a senior lecturer in organizational psychology at Griffith University. Her research interests include organizational communication, employee well-being during organizational change, and organizational identity.

Cindy Gallois is a professor of psychology at the University of Queensland. Her research focuses on intergroup communication. especially in health, organizational, and intercultural contexts. She is a fellow of the Academy of the Social Sciences in Australia.

Victor J. Callan is a professor of management at the University of Queensland Business School. His current research interests include innovation and teams, the communication of change, and community consultation in the mining industry.

Nicholas DiFonzo is an associate professor of psychology at Rochester Institute of Technology and conducts research on the psychology of rumor. 